of the two Colleges be maintained others may be added, notably one pressing for immediate solution-the attainment of power to grant medical degrees to candidates who have studied in London and qualified under the conjoint scheme. This improvement would be greatly delayed, if not prevented altogether, by admission of a new body with different views and aims, like the Society of Apothecaries, to the conjoint board. Moreover, during the negotiations which took place between the two Colleges, when arranging their compact, it was never contemplated by either body to invite the Society of Apothecaries to join in the scheme, nor did that corporation, while the negotiations were in progress, ask to be allied with the Colleges. Now that the scheme is a success, the Apothecaries want a share in it. But this application, be it remarked, was also not made until the passing of the Medical Act of 1886 compelled the Society to alter its examination under penalty of losing the power of giving a registrable qualification. Now, though the application is made, there is no suggestion as into what part of the examination, under the conjoint scheme, the Society believes its intervention would be valuable. Nor does it allege that there are subjects which have been omitted from the requirements of the conjoint scheme which ought to be included. On the contrary, that scheme is complete, and the Society would not enlarge the comprehensiveness of the examination, nor raise the standard of knowledge higher than the conjoint board hold it already. The Medical Act of 1886 has provided the Apothecaries with means for giving a registrable qualification independently of any other licensing corporation, by allowing them to obtain from the Medical Council assistant examiners in Surgery; a subject which their examinations hitherto have not touched. They have made this application, and the Medical Council in February postponed complying with it until the Colleges had been again invited to consider the practicability of admitting the Society to a share of their conjoint examination. So little expectation (possibly so little desire) had the Society that the Colleges would alter their opinions, that the Society's representative on the Medical Council voted against this appeal to the Colleges. It would seem that he desired that the Society of Apothecaries should at once acquire the power to act independently. While the Medical Act of 1886 was going through Parliament the College of Surgeons refrained from any expression of opinion respecting the propriety of preserving to the Apothecaries the power to give a registrable qualification, believing that it would be unfair to deprive the Society of this power after they had exercised it for many years. Further, to have done this would have been combating the declared object of the Act-its central idea-viz., to secure that every registered qualification should depend on a complete examination in medicine, surgery, and midwifery. The Act nowhere urges the establishment of a single portal, as it is now contended in some quarters is the object of the Medical Act of 1886 . On the contrary, it provides for failure or inability to combine which was foreseen. It is clear, then, that the Colleges are not to blame for the disappointment of those who desire unification of examining and licensing powers. The Legislature, guided by the evidence taken before it and before the Royal Commission, decided to maintain the independent action of the licensing bodies. Collegiate action had no part in this decision. Then, looking at the question from the point of public advantage, the maintenance of the Apothecaries in their power to grant their licence as a registrable qualification cannot be called a scandal without throwing a slur upon the present I. S. A.'s, which they by no means deserve. Still less when it is recollected that the future holders of this licence will be qualified in surgery as well as in medicine and midwifery, which the present holders are not. In this the public would be ganers. Further, if the Apothecaries are compelled to compete with the Colleges of Physicians and Surgeons, it must be by raising their standard of education and examination; by this change the public will again be gainers. There is no reason to expect that the two Colleges will be induced to lower their standard in order to draw candidates away from the Society of Apothecaries. In spite of competition, the College of Surgeons, for many years before it combined with the College of Physicians, and now in conjunction with that body, has gone on steadily raising the requirements for the diploma; nevertheless, probably in consequence of this increased demand from the candidates, the diplomas of the Colleges are sought by the great bulk of the medical pro- fession in England. Still more, it must not be forgotten that there is a large number of respectable medical practitioners whose powers or opportunities for study have been insufficient to enable them to pass the examinations of the two Colleges. Such men have been compelled to go to Glasgow, Edinburgh, or Dublin, where they have been able to qualify after repeated rejections in London. For such persons (by no means merely idle, careless students) the licence of the Apothecaries' Society will in future afford a means for entering the roll of practitioners and occupying a worthy position thereon. A further argument put forward by the Apothecaries for their admission to the Conjoint Examining Board is that the existence of the Society will thereby be assured, and with its assured existence the Society's power to prosecute irregular practitioners will be secured. Now, it may be remarked that this argument is put forward by those very advocates who contend that the Apothecaries would still contrive to exist even if left to act independently in granting licences, and that the two Colleges might suffer harm through its independent and competitive action. But it is very doubtful if this resolution of the two Colleges will shorten the life of the Apothecaries' Society, or that the continued career of the Apothecaries' Society will be injurious to the two Colleges. Even if the Society should become extinct as a power in medical politics, the authority to prosecute irregular practitioners could be conferred on some other body-the Medical Council, for example; it would not be allowed to drop.

I am, Sirs, yours truly, BERKKLEX HILL,

\section{THE THEORY AND TREATMENT OF PLACENTA} PRAVIA.

To the Editors of THE LANCET.

Srrs,--I hope it will not be considered superfluous on my part if I offer a few observations upon this grave complication of pregnancy in addition to the very interesting letters of Dr. James Murphy (The LaNCET, March 12th) and Dr. Braxton Hicks (Ture LANCET, March 26th), Both letters bear testimony to the command achieved by modern science over a complication long marked by disaster to mother and child. So long as the false and appalling doctrine of "unavoidable hemorrhage" approved by Levret, Rigby, Denman, Cazeaux, and Gardien prevailed, which assumed that there could be no arrest of bæmorrhage until labour was completed, brutal logic compelled instant resort to the accouchement forcé. Thus, all opportunity of observing the ways of nature and arriving at the true theory of placenta prævia was barred. The theory of "unavoidable hæmorrhage" translated into practice meant violent delivery, by forcing the hand through the cervical canal, dilated or not dilated, seizing the child and dragging it away. The happy discovery of Dr. Braxton Hicks of the bimanual-or, as I prefer to call it, the bipolar-method of turning has rendered the violent method of delivery unnecessary and unjustifiable. As I hare said ("Obstetric Medicine and Surgery"), "Braxton Hicks' bimanual operation here finds one of its most useful applications." But it is only an application. It cannot be raised to the rank of the treatment of placenta prævia. This practical question is not so simple. Rational treatment must be based upon true theory and correct clinical observation. Clinical observation led Puzos, Wigand, d'Outrepont, Robert Lee, Mercier, myself, and others to recognise cases in which continuous bæmorrhage did not occur, and in which nature could be trusted. Still, it was not until 1847, when I first enunciated the new theory of placenta prævia in THE LANCET, that the more intelligent and successful principles of practice fairly made way. In 1844-45 Sir James Simpson, adopting the view of Kinder Wood, Radford, and Hamilton, that the source of the bleeding was the placenta, logically concluded that the right treatment was to wholly detach the placenta. The theory was wrong, and the practice worse than the old accouchement forcé. Since the total detachment of the placenta could hardly be accomplished without forcing the whole hand into the uterus. Fraught with peril to the mother, it was almost certainly fatal to the child. I mention this because it has been said in your issue of Feb. 26 th that "Barnes' treatment--partial detachment"-is a modification of Simpson's. My theory and practice differ toto coelo from Simpson's. I have taken special pains to show that the source of the 
hæmorrhage is the same as that in post-partum hæmorrhagenamely, the uterus. Having cleared the ground of this misapprehension, let me state as briefly as it is possible the theory and practice now generally accepted. The uterus is divided into three zones - the fundal, the equatoria], and the lower. It is only placenta attached within the lower zone that makes placente prævia. There is no necessary detachment of placenta attached to the two upper zones. The limits of the lower zone, that of dangerous placental attachment, are the os internum below and a circle closely defined by the equator of the child's head above. I must refer to my systematic works for the evidence of this. It is enough here to state that this boundary line was revealed to me by repeated clinical observation and deduction; and that this physiological discovery has since been confirmed by the anatomical researches of Bandl. In fact, Bandl's ring is identical with my boundary line between the lower and equatorial zones.

Treatment, then, flows from the fact that hæmorrhage often ceases when all placenta, or sometimes only a great part of it, growing within the lower zone, has been detached, active or passive uterine contraction taking place. Action is conducted on the following lines. Provoke uterine contraction. To do this we have first the old plan. (1) Puncture the membranes. (2) Apply a tirm binder over the uterus. (3) If the cervix is small and rigid, pass a laminaria tent to dilate, watching carefully. (4) Pass in one or two fingers and detach all placenta within reach of the fingers. The sweep of the fingers very closely takes the lower zone. (5) Insert a Barnes' bag. This acts in three ways: it dilates the cervix; it provokes uterine action; it acts as a plug, compressing the mouths of the bleeding vessels. Now things are prepared for delivery. If the head presents, (6) apply forceps, or turn by the bipolar method. This plan gives the greatest security to the mother, and the best chance to the child.

In a typical case, coming under care from the beginning, all these expedients may come into use in succession. In those cases where we are called when flooding is furious, it may be necessary to introduce the hydrostatic dilator at once, or if the cervix is dilated enough - and very moderate dilatation is enough -it is advisable to turn. I will not trouble you with statistics. These have been sufficiently quoted by Dr. Murphy and Dr. Braxton Hicks. I believe that a wider adoption of the principles enunciated above will produce figures more satisfactory still.

$$
\text { I am, Sirs, yours faithfully, }
$$

Harley-street, March, 1887 ROBERT BARNES.

\section{THE SOCIETY OF APOTHECARIES AND THE CONJOINT BOARD FOR ENGLAND. To the Editors of THE LANCET.}

SIRS,--May I be allowed to express my opinion on the question of admitting the Apothecaries Society into the Conjoint Examining Board, as one of the licentiates of that Society. In 1860, after examination, being permitted to practise medicine within ten miles of London (an antiquated restriction), I was duly impressed with the high opinion entertained by boards of guardians of the L.S.A. qualification-an estimate to which I do not at present attach a high value. But now this handmaid of a wholesale and retail drug-shop is struggling to mix up surgery in the concern, and to force herself into society where she is not welcome. These futile efforts are, perhaps, allied to the erratic movements which frequently precede dissolution. In my opinion, the Apothecaries' Hall should ally herself with the Pharmaceutical Society, and should no longer perpetuate (by her association with our profession) one of the most vulgar prejudices that $I$ have had and yet have to fight against-viz., the persistent idea that drugs occupy the first place in our treatment of disease. While rendering to the Society of Apothecaries full credit for her early improvements in education, I submit that, in the highest and best interests of our profession, now is a fitting time for a divorce; the Hall has her own proper course to hold, but on matters of high training, example, and social prestige, she may now write on her walls "Obsoleta per orbem dicor." I am, Sirs, your obedient servant,

RTCHARD DAVY, Surgeon to the Westminster Hospital.

Welbeck-street, W., March 25th, 1887.

\section{THE QUESTION OF RELATIVE RANK. To the Editors of THE LANCET.}

Sirs,-Touching the question of relative rank in the army, and the desire, apparently on the part of some medical officers to have their titles compounded of a medical and distinctive military one, I would like to ask, Is it not an undignified and false position for members of the medical profession to lead the public to believe that they cannot, as such, stand alone, but need the support of the reflected advantages of purely military titles, indicative of and appertaining to a profession to which they do not rightfully belong? What can the public think of such a proceeding? And, as a matter of policy or expediency, why should a Doctor of Medicine or a Fellow of the Royal College of Surgeons seek to obtain such titles?

March, 1887. I am, Sirs, yours faithfully,

F. R. C.P.

To the Editors of THE LANCET.

SIRs,- The abolition of "relative rank" in the army has not, as pointed out by you in a late number of THE LANCET, altered in any way practically the "status" of officers of the medical staff, but their position in the army remains as heretofore unsatisfactory and undefined, for "relative" rank is but a meaningless term, and carries with it no military rank. Now, why should the officers of the medical department be the only officers in the army who have no military standing, honorary or otherwise? Apart from their purely professional duties they have distinct military duties to perform-when doing duty with the Medical Staff Corps at headquarters, or in command of "detachments " of that corps, or on active service when attached to " bearer companies." Why, therefore, if called upon to perform purely military duties, are they not granted military rank? The quartermasters, warrant, and non-commissioned officers, \&c., of the Medical Staff Corps have a defined military "status," but the officers who command them have no military rank. Surely this is an anomaly. Is the medical department not a necessary and integral part of the army organisation, and are the officers of that department any less entitled to a proper locus standi in the service than officers of other departments? Again, is the medical department a military or a purely civil department. If the latter, why should the medical officers be called upon to wear military uniform and to exercise military command over their corps? In desiring "honorary" rank, as giving them a defined military "status" in the army, the officers of the medical staff have no wish whatsoever to represent themselves otherwise than as medical men. They are proud of the noble profession of which they have the honour of being members, and would be sorry to lose the "title" of "surgeon," which distinguishes them from the regimental officer holding "substantive" rank. I would venture to suggest that "honorary" rank be granted to medical officers, the terms "surgeon-captain," "surgeon-major," up to "surgeon-general" being retained, the first part of the title showing that the officer was a medical officer, and the second part the honorary rank which such officer held in the army. In conclusion, I would add that the assertion which has been made that medical officers are. desirous of obtaining purely military titles is erroneous and absurd, for they have nothing to gain and much to lose by obscuring the fact that they are medical men.

March, 1887. MEDICAI STAFF。 I am, Sirs, yours obediently

\section{EDINBURGH.}

(From our own Correspondent.)

THE SCARLET FEVER RPIDEMIC.

IN connexion with the statement in my last week's note upon this subject, some doubt has been thrown upon the results of the investigation then detailed. It was reported that the source of the outbreak had been detected, and that the disease had been clearly traced to a dairy-farm in the country, from which a large part of the Edinburgh milksupply is derived. The proprietor of this farm now writes 